\title{
Novel Permanent Magnet Synchronous Motor with Integrated Filter Inductor, Using Motor's Inherent Magnetics
}

M. Raza Khowja, Chris Gerada, Senior Member, IEEE, Gaurang Vakil, Member, IEEE, Chintan Patel, Member, IEEE, Shafiq Odhano, Member, IEEE, Adam Walker and Pat Wheeler, Senior Member, IEEE

\begin{abstract}
A close functional and structural integration of passive elements is required to improve the power density of motor drives. Such power dense motor drives are prerequisite in aerospace and automotive applications. This paper presents a permanent magnet motor with integrated filter inductor, which not only eliminates inductor losses but also removes its associated weight and volume. The motor with integrated filter uses motor's inherent magnetics in order to use it as a filter inductance instead of adopting an external inductor option, which is traditionally placed outside the motor. A vector-controlled model, taking modulation and switching effect into account, has been developed by using MATLAB/Simulink tool. To experimentally validate the concept of the motor with integrated filter inductor, the winding connections of an existing motor are modified. The comparative analysis, between the traditional and integrated motor drive systems, is carried out in terms of magnitude of switching component, total system losses, weight and volume. The total losses in the motor with integrated filter are reduced by $34.2 \%$ at 2100rpm and $3 \mathrm{Nm}$ load, when compared to the motor with traditional filter inductor, whereas, its weight and volume in the motor with integrated filter inductor is eliminated completely.
\end{abstract}

Index Terms - Aerospace industries, passive elements, integrated motor drive, traditional motor drive, switching component, integrated inductor and external inductor.

\section{INTRODUCTION}

$\mathrm{P}$ assive components within the motor drive system are used for filtering purpose to meet the power quality standards on the supply side and to minimise losses, ripple current and protect the winding's insulation on the machine side. Passive filter inductors occupy a significant amount of space in motordrives which ultimately pays the price of having increased weight, volume and overall system losses. These components are widely used in power generation and motor-drive systems, including automotive and aircraft applications that contribute a substantial portion of converter's weight and volume, potentially larger than $50 \%$ of the mass [1-4].

Traditionally, the filter inductors are designed and introduced into the system after motor-drive components have been defined which leads to a discrete sub-system. Therefore, close structural and functional integration is necessary to make a compact and efficient motor-drive system. Such compact systems are prerequisite in aircraft and automotive applications. In order to overcome these downsides, the integration of passives needs to be introduced from functional and physical point of view [4-9].

In recent times, the passive integration has been focused on power electronics and motor drive applications that results in

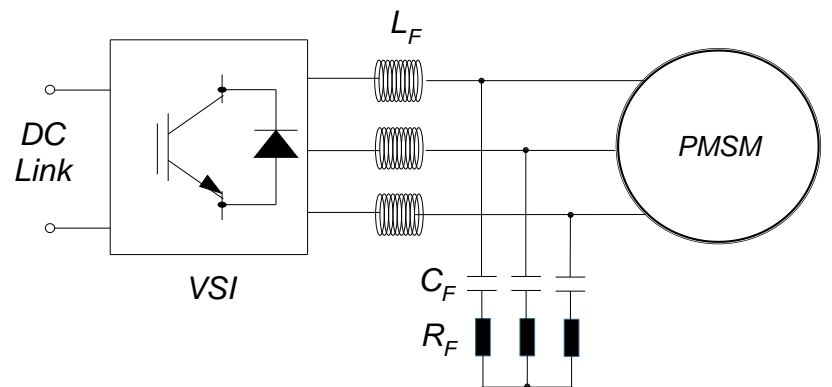

Fig. 1: Conventional PMSM Drive System with RLC Output Filter an overall compact and power dense system. In [6], a novel approach to integrate the inverter output filter inductor is presented for PMSM motor-drives. The proposed motor uses the inherent motor magnetics as a filter inductance instead of using an external filter inductor. This leads to the elimination of power losses in the external inductor and its associated mass and volume. There are two downsides of this approach - one is the difficulty in the control system design if the phase shift between filter and motor branch currents is large (or the filter capacitance is too big). However, since the RLC filter (i.e. RLC filter circuit as a whole) is designed to act as a high impedance network at low frequencies and present low impedance at higher frequencies, the large phase shift or big capacitance values are unlikely. Secondly, the filter branch winding is still exposed to the PWM voltages and currents which requires good electrical insulation system, to protect the windings against high voltage gradient $(\mathrm{dv} / \mathrm{dt})$. This is only required if the electrical insulation does not comply with the $\mathrm{dv} / \mathrm{dt}$ of the power switches. In [7-9], novel options to integrate the passive filter inductors were introduced within the housing of the motor or generator. The novel options include: motor-shaped rotational inductor and motor-shaped rotor-less inductor. Both inductors were integrated axially alongside the electrical machine within the common housing which results in a shared cooling system. Hence, eliminates the requirement of a separate cooling system for the filter inductor, if designed for high current densities. The rotor of the rotational inductor rotates at the synchronous speed of the stator magnetic field to minimise iron losses through the rotor. On the other hand, the rotor-less inductor has a similar structure but without the rotor which makes it suitable for DCLink smoothing inductors, grid input filters and isolation transformers. In contrast, the rotational inductor can only be adopted for the applications of high-speed motor drives, to minimise higher portion of the iron loss in the rotor circuit. The perspectives on the integrated filter inductors that motivate the drive integration on a system level are presented in [13-15]. The design of integrated filter inductor for power factor correction 
application is presented in [13]. The paper modified the stator laminations to increase the stator back iron which acts as an integrated filter inductor. This modification increases the outer diameter of the motor which eventually reduces the power density of the motor drive system. In [14-15], the entire stator back iron is utilised as a magnetic part for one or more discrete inductors by integrating toroidal windings, which push the alternating magnetic flux in the complete loop through the back iron of the stator core. If the stator back iron of the machine is operating linearly then the presence of ring flux due to toroidal winding will not affect the main flux. Authors of $[16,17]$ presented a structural integration of grid side passive LCL filter into the high-speed PMSM which achieves high power density. Both inductors are wound into the outermost slots of the double slot machine. The proposed integrated inductor is iteratively optimised in terms of iron and copper weight and compared with the traditional filter inductor. The integrated filter inductors on the outermost slots are free from cross-coupling of magnetic fields between the main machine and filter winding. This is done by adopting different pole numbers of filter winding to that of torque producing motor windings.

The objective of this paper is to experimentally validate the concept of using inherent motor's magnetics as an integrated filter inductor, instead of introducing the inductor outside of the motor. This is done by connecting the filter capacitance between motor windings to filter out the high frequency PWM voltages and currents for the motor branch. In the next section, the design methodology of an output filter is presented followed by the details of the motor with integrated filter inductor. In section III, mathematical equations of the motor with integrated filter inductor have been derived to model it in MATLAB/ Simulink tool. A detailed vector control model of the motor with integrated filter inductor, considering modulation and device switching, has been developed. Subsequently, the practical implementation of how the existing motor is converted into the motor with integrated filter inductor is presented. Section IV validates the MATLAB/Simulink results with the experimental study of both motor with traditional and integrated filter inductors, followed by the comparison of total system losses, weight and volume of both the motor-drive systems. Finally, the paper is concluded in section $\mathrm{V}$ followed by the future work in section VI.

\section{OUtPUT FILTER Design}

The RLC output filter, as shown in Fig. 1, is the traditional practice to mitigate the inverter switching frequency harmonics injecting into the electrical machines. The RLC output filter is designed by specifying the resonance frequency of the filter and the resonance arising between the filter capacitance and motor windings inductance. The filter capacitance should be carefully chosen such that resonance between motor inductance and the filter capacitance $\left(\mathrm{C}_{\mathrm{F}}\right)$ does not interfere with the control loop [18]. Therefore,

$$
C_{F} \leq \frac{1}{\left(2 \pi f_{\max }\right)^{2} \cdot L_{m}}
$$

Where $\mathrm{f}_{\max }$ is the maximum frequency that the control loop is able to reject and $\mathrm{L}_{\mathrm{m}}$ is the main inductance of the machine.
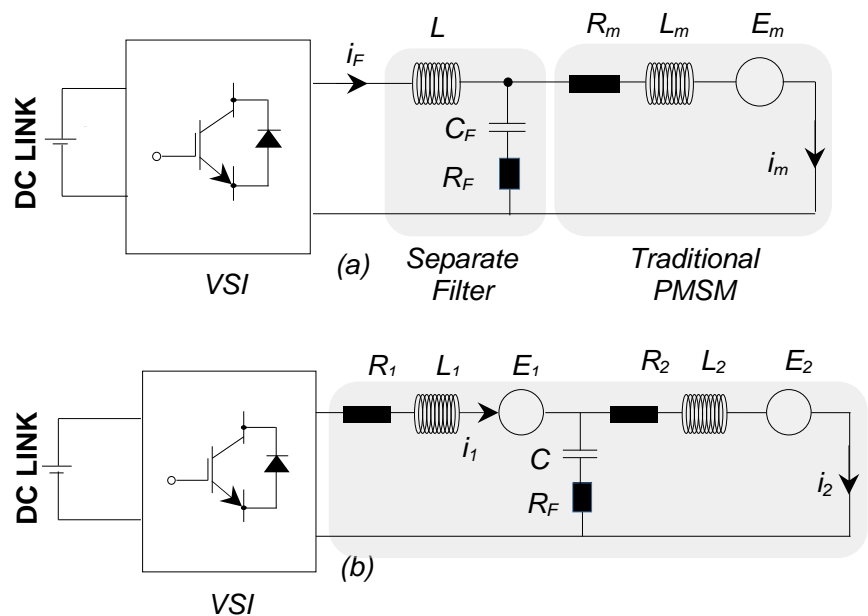

Fig. 2: Traditional and integrated PMSM drive system (a) with conventional separate filter (b) with integrated filter

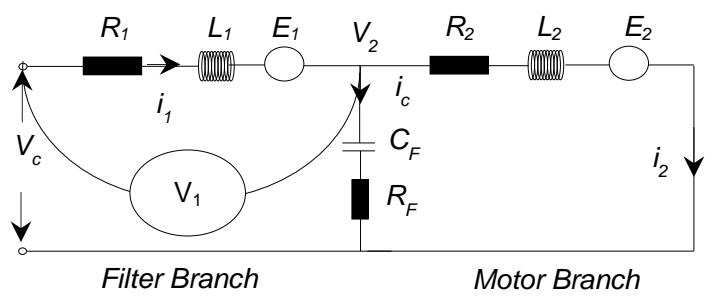

Fig. 3: Per phase Equivalent Circuit (a) Filter Branch (b) Motor Branch

TABLE I

PARAMETERS OF TRADITIONAL \& INTEGRATED MOTOR DRIVE

\begin{tabular}{lll}
\hline PARAMETERS & QUANTITY & UNIT \\
\hline DC Bus Voltage & 200 & $\mathrm{~V}$ \\
Fundamental Frequency & 0.175 & $\mathrm{kHz}$ \\
Control Loop Frequency & 1 & $\mathrm{kHz}$ \\
Switching Frequency & 10 & $\mathrm{kHz}$ \\
Number of Turns per phase & $2 \times 46$ & - \\
Operating Torque & $1-3$ & $\mathrm{Nm}$ \\
Operating Speed & $1200-2100$ & $\mathrm{RPM}$ \\
Phase Resistance & $2 \times 0.25$ & $\Omega$ \\
Phase Inductance & $2 \times 1.3$ & $\mathrm{mH}$ \\
No-load Flux Linakge & $2 \times 0.017122$ & $\mathrm{Vs}$ \\
Rated Speed & 5252.5 & $\mathrm{RPM}$ \\
Rated Torque & 4 & $\mathrm{Nm}$ \\
\hline
\end{tabular}

\section{A. Resonance Frequency Selection}

The selection of the resonance frequency is a trade-off between the degree of switching harmonics mitigation and size of filter components. Lower the resonance frequency, lower will be the switching harmonics in the motor voltages/currents. Preferably, the impedance of the RC branch should be a fraction of the motor impedance at resonance frequency so that most of the unwanted switching harmonics are passed through the RC branch. The resonance frequency of the filter is given by,

$$
f_{\text {res }}=\frac{1}{2 \pi \sqrt{L_{F} C_{F}}}
$$

To select resonance frequency there are several approaches. In $[11,12]$, it is recommended to choose a resonance frequency ten times higher than fundamental frequency of the motor current and $1 / 3$ times less the inverter switching frequency. This gives the upper and lower bound for resonance frequency as, 


$$
10 f_{\text {out }}<f_{\text {res }}<\frac{1}{3} f_{\text {sw }}
$$

In order to damp the oscillation of the output filter, the damping resistance is added in series with the filter capacitance which attenuates the unwanted oscillation at the resonance frequency. The value of this resistor is determined as one third of the filter capacitance impedance at the resonance frequency [19],

$$
R_{\text {damp }}=\frac{1}{3 \omega_{\text {res }} C_{F}}
$$

The resonance frequency of the output filter is fixed to $2 \mathrm{kHz}$, whereas, the maximum frequency $\left(f_{\max }\right)$ of $1.2 \mathrm{kHz}$ is chosen to avoid the resonance between the filter capacitance and the motor inductance. Based on the resonance frequency, the filter inductance and capacitance are estimated as $1.3 \mathrm{mH}$ and $4.9 \mu \mathrm{F}$. The resistance of $2 \Omega$ is chosen to damp the oscillations which is approximately $1 / 8^{\text {th }}$ of the filter capacitance impedance.

\section{Motor WITH INTEGRATED FILTER INDUCTOR}

The motor with integrated filter inductor utilizes the inherent motor magnetics as filter inductance, instead of introducing a discrete filter inductor between the inverter and motor terminals. Fig. 2(a)-(b) shows both traditional and integrated motor drive systems respectively. It is shown that the motor with integrated inductor does not include a discrete inductor thus eliminating added filter inductor losses and its associated weight and volume. Filter capacitor and damping resistor are placed between the motor windings to form an integrated RLC output filter using the inductance of motor windings. The value of the filter inductance can be varied - by varying proportion of the motor winding used as a filter and varying the capacitance of the integrated RLC filter for the same resonance frequency.

\section{A. Filter and Motor Branch}

The motor with integrated filter inductor is divided into two branches i.e. filter branch and the motor branch as shown in Fig. 3. The windings in the motor branch experience the sinusoidal currents and voltages due to the filtering effect. On the other hand, the currents with PWM switching component flows through the filter branch winding, which is a fraction of the entire motor windings.

\section{B. Vector Control Modelling}

A detailed vector control model of the motor with integrated filter inductor, taking into account of modulation and device switching, has been developed using MATLAB/Simulink tool as shown in Fig. 4. A 12 slot, 5 pole-pair surface-mounted PMSM is considered, for both traditional and integrated motordrive systems, the specification details of which are shown in Table I. Since both the motor-drive systems having the same machine the only change is the filter components i.e. traditional and integrated inductors. The mathematical model is based on "abc" reference frame. The "abc" currents are transformed into d-q reference frame for control purpose. As the number of turns per phase in filter branch and motor branch are identical, i.e. $50 \%$ of the total number of turns, the filter branch currents are controlled to produce maximum torque from the filter branch, however, the motor branch is left uncontrolled to avoid the need of additional current sensors. The motor branch current may be controlled to produce the maximum torque, if the current sensors are placed in the motor branch leaving the filter branch uncontrolled. The filter capacitor and damping resistor are connected in between the filter and motor branch. It should be noted that, inserting filter capacitance and resistance between the filter branch and the motor branch will introduce a phase shift between two branch currents, i.e. $i_{1 \text { abc }}$ and $i_{2 a b c}$. Therefore, analysis phase-shift is a must check whilst implementing the integrated inductor inside the machine.

The mathematical equations, needed to model the motor with integrated filter inductor, are obtained by using the per phase equivalent circuit. The per-phase equivalent circuit of the motor with integrated filter inductor is shown in Fig. 3. By applying mesh analysis on filter branch (Fig. 3) we have:

$$
\begin{aligned}
V_{1 a}(t)=R_{1} i_{1 a}+ & L_{1} \frac{d}{d t} i_{1 a}+\frac{d}{d t} \psi_{1} \cos \theta_{e} \\
& +\frac{1}{C_{F}} \int\left(i_{1 a}-i_{2 a}\right) d t+R_{F}\left(i_{1 a}-i_{2 a}\right)
\end{aligned}
$$

Converting (5) into s-domain by taking Laplace transformation on both sides we have:

$$
\begin{gathered}
V_{1 a}(s)=R_{1} i_{1 a}+L_{1} i_{1 a} s-\omega_{e} \psi_{1} \sin \theta_{e}+\frac{1}{C_{F} s}\left(i_{1 a}-i_{2 a}\right) \\
+R_{F}\left(i_{1 a}-i_{2 a}\right)
\end{gathered}
$$

Solving for $\mathrm{i}_{1 \mathrm{a}}$

$$
\begin{gathered}
i_{1 a}=\frac{1}{s L_{1}}\left(V_{c a}+\omega_{e} \psi_{1} \sin \theta_{e}-R_{1} i_{1 a}-R_{F} i_{1 a}+R_{F} i_{2 a}\right. \\
\left.-\frac{1}{s C_{F}} i_{1 a}+\frac{1}{s C_{F}} i_{2 a}\right)
\end{gathered}
$$

The currents of phase $b$ and $c$ with $\pm 120^{\circ}$ phase shifts are:

$$
\begin{gathered}
i_{1 b}=\frac{1}{s L_{1}}\left(V_{c b}+\omega_{e} \psi_{1} \sin \left(\theta_{e}+\frac{2 \pi}{3}\right)-R_{1} i_{1 b}-R_{F} i_{1 b}\right. \\
\left.+R_{F} i_{2 b}-\frac{1}{s C_{F}} i_{1 b}+\frac{1}{s C_{F}} i_{2 b}\right) \\
i_{1 c}=\frac{1}{s L_{1}}\left(V_{c c}+\omega_{e} \psi_{1} \sin \left(\theta_{e}-\frac{2 \pi}{3}\right)-R_{1} i_{1 c}-R_{F} i_{1 c}\right. \\
\left.+R_{F} i_{2 c}-\frac{1}{s C_{F}} i_{1 c}+\frac{1}{s C_{F}} i_{2 c}\right)
\end{gathered}
$$

Similarly, for the motor branch we have:

$$
\begin{aligned}
0=R_{2} i_{2 a}+L_{2} & \frac{d}{d t} i_{2 a}+\frac{d}{d t} \psi_{2} \cos \theta_{e} \\
& +\frac{1}{C_{F}} \int\left(i_{2 a}-i_{1 a}\right) d t+R_{F}\left(i_{2 a}-i_{1 a}\right)
\end{aligned}
$$

Converting (10) into s-domain by taking Laplace transformation on both sides we have:

$$
\begin{gathered}
0=R_{2} i_{2 a}+L_{2} i_{2 a} s-\omega_{e} \psi_{2} \sin \theta_{e}+\frac{1}{C_{F} s}\left(i_{2 a}-i_{1 a}\right) \\
+R_{F}\left(i_{2 a}-i_{1 a}\right)
\end{gathered}
$$




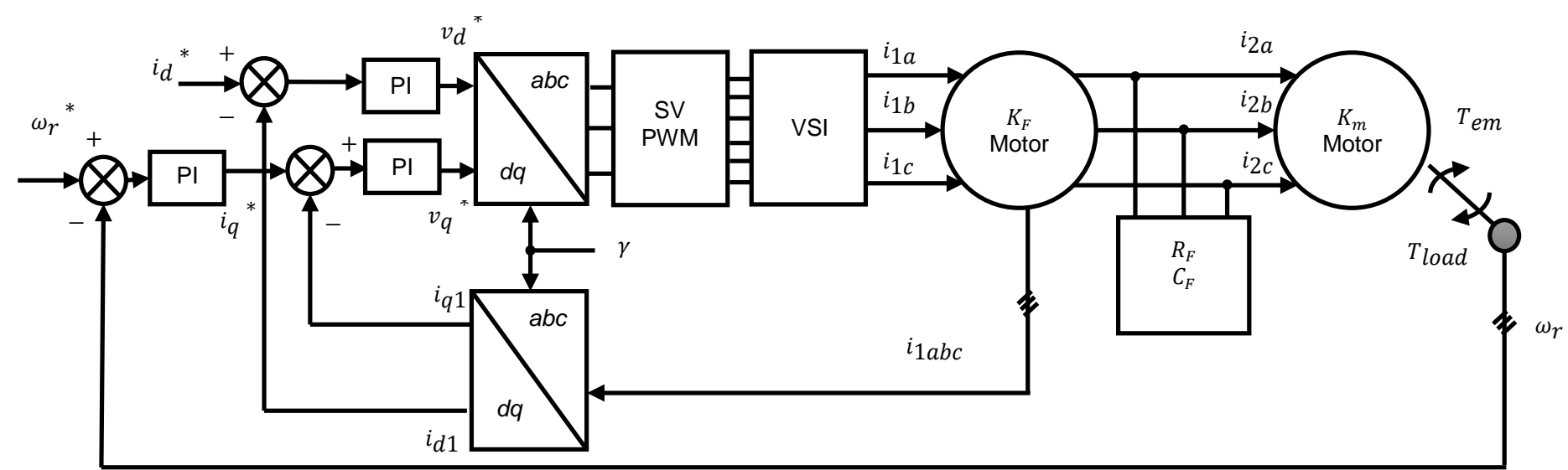

Fig. 4: Control block diagram of the proposed motor with integrated inductor

Solving for $\mathrm{i}_{2 \mathrm{a}}$,

$$
\begin{gathered}
i_{2 a}=\frac{1}{s L_{2}}\left(0+\omega_{e} \psi_{2} \sin \theta_{e}-R_{2} i_{2 a}-R_{F} i_{2 a}+R_{F} i_{1 a}\right. \\
\left.-\frac{1}{s C_{F}} i_{2 a}+\frac{1}{s C_{F}} i_{1 a}\right)
\end{gathered}
$$

The currents of phase $b$ and $c$ with $\pm 120^{\circ}$ phase shifts are:

$$
\begin{gathered}
i_{2 b}=\frac{1}{s L_{2}}\left(0+\omega_{e} \psi_{2} \sin \left(\theta_{e}+\frac{2 \pi}{3}\right)-R_{2} i_{2 b}-R_{F} i_{2 b}\right. \\
\left.+R_{F} i_{1 b}-\frac{1}{s C_{F}} i_{2 b}+\frac{1}{s C_{F}} i_{1 b}\right) \\
i_{2 c}=\frac{1}{s L_{2}}\left(0+\omega_{e} \psi_{2} \sin \left(\theta_{e}-\frac{2 \pi}{3}\right)-R_{2} i_{2 c}-R_{F} i_{2 c}+R_{F} i_{1 c}\right. \\
\left.-\frac{1}{s C_{F}} i_{2 c}+\frac{1}{s C_{F}} i_{1 c}\right)
\end{gathered}
$$

\section{Practical Implementation}

The practical implementation of the motor with integrated filter inductor is illustrated in Fig. 5. The motor is 12 slots, single layer, and 5 pole-pair, whilst, employing the concentrated windings for both filter and motor branches. The rotor is in "Halbach array" arrangement that gives higher torque density and increased efficiency. Due to halbach array arrangement, the permanent magnets are mounted directly onto the shaft to save the rotor mass. Entire motor winding is divided into filter and motor branch. The filter branch uses a part of the motor winding as a filter inductance. This forms a part of integrated RLC output filter that attenuates the harmonic frequencies (switching frequency and its side bands) for a given resonance frequency. In Fig. 5, the vectors A1, B1 and C1 represent the filter branch, whereas, the vectors $\mathrm{A} 2, \mathrm{~B} 2$ and $\mathrm{C} 2$ correspond to the motor branch. The vectors (A1, B1 and C1) of filter branch and the motor branch are wound in such a way that the flux generated by both the windings are additive. The value of filter inductance is fixed by the filter design process, as explained in section II. Initially, the motor has a total inductance of $2.6 \mathrm{mH}$ and 92 turns per phase. The required inductance of $1.3 \mathrm{mH}$ is considered for filter branch leaving $1.3 \mathrm{mH}$ for the motor branch. The filter branch is not tapped since the required filter inductance is exactly half of the total inductance of the motor winding.

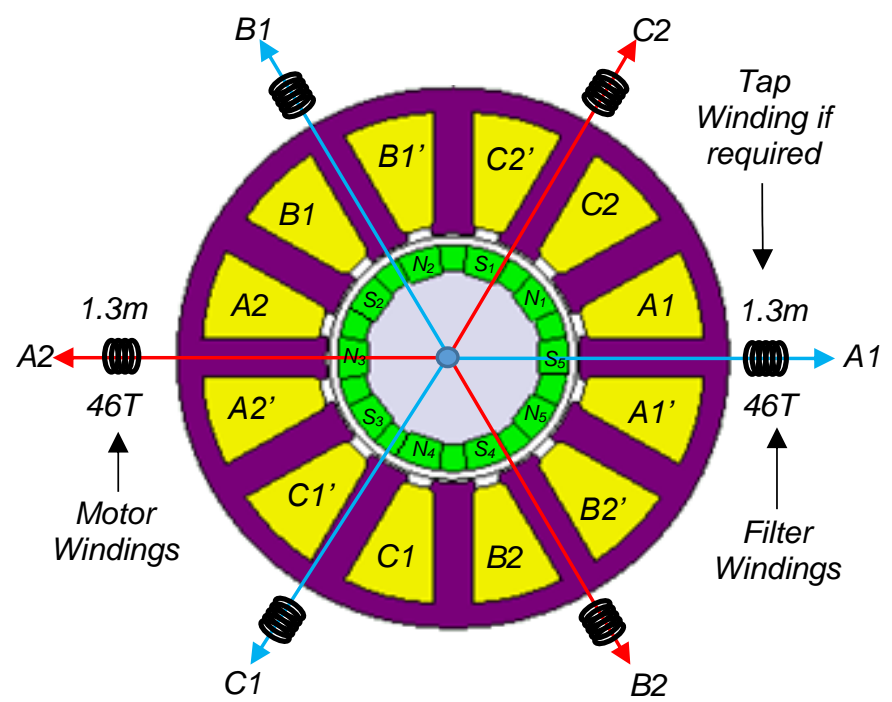

Fig. 5: FE Model of 12S/10P Permanent Magnet Synchronous Motor

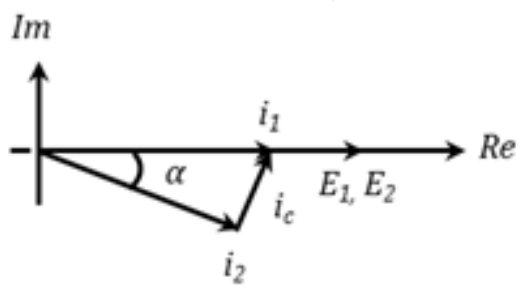

Fig. 6: Phase Diagram of Filter and Motor Branch Current

\section{Electromagnetic Torque}

The electromagnetic torque developed by the traditional surface mounted PM synchronous motor is given by,

$$
T_{e m}=K \psi_{m} i_{a}
$$

Since there are now two torque components, (15) is not valid to estimate the electromagnetic torque. The torque components developed by the motor with integrated filter inductor are:

1. Torque due to the filter branch winding, $T_{a 1}$ and,

2. Torque due to the motor branch winding, $T_{a 2}$

Therefore, the electromagnetic torque developed by the motor with integrated filter inductor is,

$$
\begin{gathered}
T_{e m}=T_{a 1}+T_{a 2} \\
T_{e m}=K\left(\psi_{1} i_{1}+\psi_{2} i_{2} \cos \alpha\right)
\end{gathered}
$$




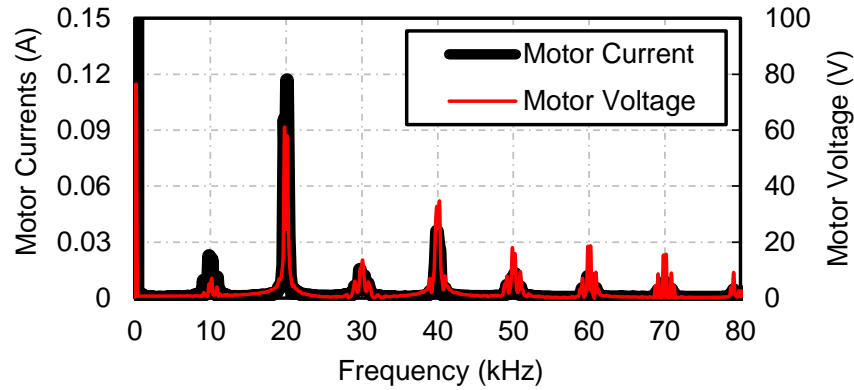

Fig.7: Simulink results of the motor without Output Filter (a) FFT of inverter voltage and FFT of motor current
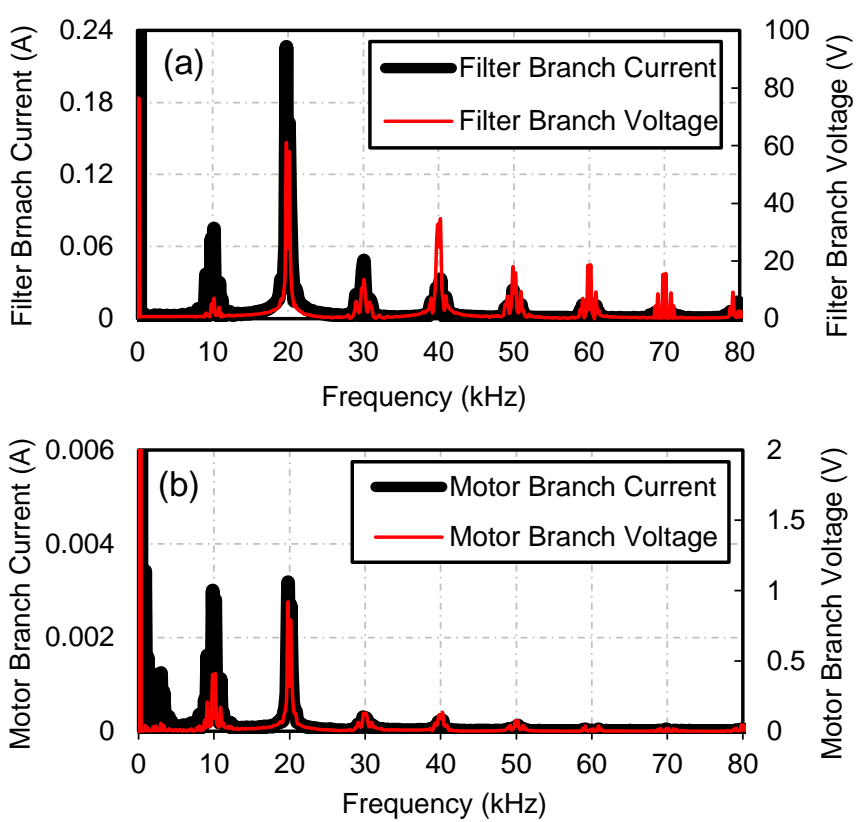

Fig.8: Simulink results of the motor with Integrated Filter Inductor (a) FFT of inverter voltage, $\mathrm{V}_{\mathrm{C}-\mathrm{AB}}$ and FFT of filter branch current, $\mathrm{i}_{1}$ (b) FFT of motor branch voltage, $\mathrm{V}_{2}, \mathrm{~V}_{2}$ and FFT of motor branch currents, $\mathrm{i}_{2}$
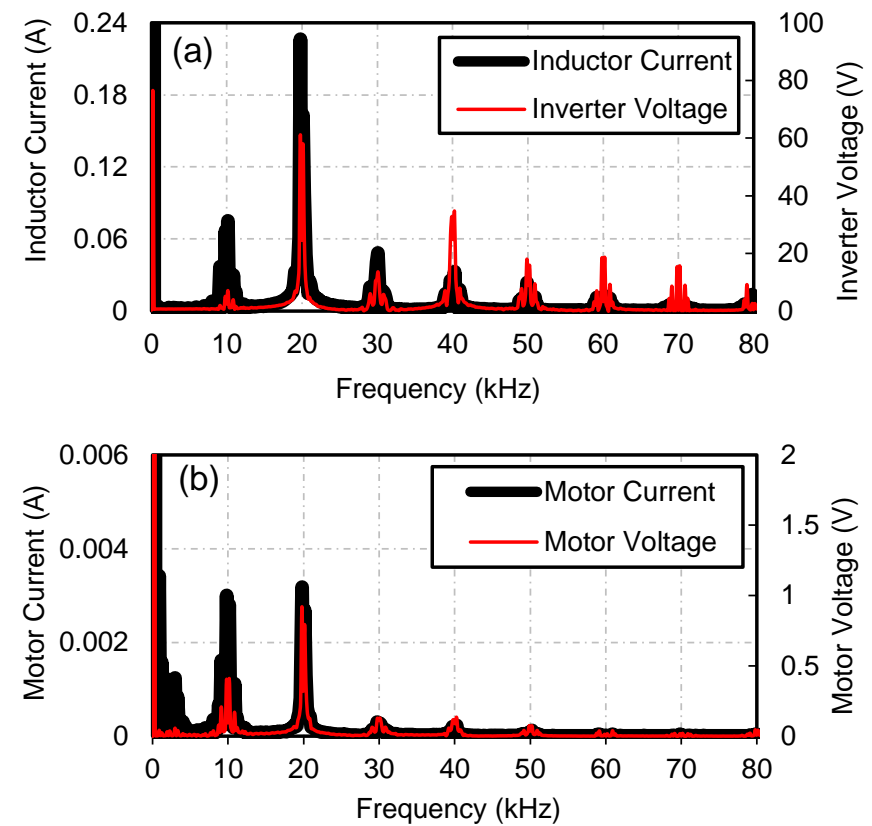

Fig.9: Simulink results of the motor with Traditional Filter Inductor (a) FFT of inverter voltage, $\mathrm{V}_{\mathrm{C}-\mathrm{AB}}$ and FFT of inductor current, $\mathrm{i}_{\mathrm{F}}(\mathrm{b})$ FFT of motor branch voltage, $\mathrm{V}_{\mathrm{M}}$ and $\mathrm{FFT}$ of motor currents, $\mathrm{i}_{\mathrm{M}}$,
Referring to the Fig. 6, the phase shift angle $\alpha$ between two currents is calculated as,

$$
\alpha=\cos ^{-1}\left(\frac{i_{1}^{2}+i_{2}^{2}-i_{c}^{2}}{2 i_{1} i_{2}}\right)
$$

This electromagnetic torque will cause the speed response, which is defined by,

$$
\omega_{r}=\frac{1}{J s}\left(T_{e m}-T_{\text {load }}\right)
$$

\section{E. MATLAB/Simulink Results}

The MATLAB/Simulink results of the motor are presented in this section, operating without a filter, with the integrated filter and with a traditional filter. The motor is driven by the voltage source inverter, while switching and modulation effects taken into account, with the space vector modulation technique adopted. In all the cases, the motor is operating at maximum speed of $2100 \mathrm{RPM}$ and mechanical load of $1.5 \mathrm{Nm}$.

Fig. 7 shows the FFT of the inverter terminal voltage and the motor current, when the motor is operating without output filter. The Simulink results (FFT) of the motor with integrated filter inductor (Fig 2b) and the motor with traditional filter inductor (Fig 2a) are shown in Fig. 8 (a)-(b) and Fig 9 (a)-(b) respectively. The design of traditional filter inductor, (i.e. EEcore inductor) presented in [7] is chosen for the purpose of comparing integrated and traditional motor-drive systems whilst keeping the filter inductance of $1.3 \mathrm{mH}$ (i.e. $\mathrm{L}_{\mathrm{F}}=\mathrm{L}_{1}$ ). It is shown from Fig. 8(b) and Fig. 9(b) that the filtering effect of the motor with integrated filter inductor and the motor with traditional EE-core inductor are alike, since the inductance seen by the inverter terminals is same, in both the motor-drive systems. The Simulink results of the motor with integrated filter inductor (Fig. 8) have shown that the half of the motor winding experiencing the filtered voltages. Thereby, lessening the high gradient voltage stress and high frequency PWM losses in half of the motor windings. It is important to note that the high gradient voltage drops across the filter branch winding, therefore, the insulation system of the filter branch may be made high to bear the PWM voltage stress, if it is not compliance with the $\mathrm{dv} / \mathrm{dt}$ of the power switches.

In this study, the motor winding inductance is halved to use it as filter inductance, however, the filter winding can be split into any required ratio so that higher portion of the motor windings experiences the filtered currents and voltages. In this case, filter capacitance may be increased for a given resonance frequency, which is given by the relation,

$$
\omega_{\text {res }}=\sqrt{\frac{1}{L_{1} C_{F}}}
$$

\section{EXPERIMENTAL VERIFICATION}

This section presents the experimental verification of the motor with integrated filter inductor which was proposed in [6]. In order to verify the concept of integrated motor, the HEMAS (Helicopter Electro-Mechanical Actuation System) motor was used, that was recently built in our University for HEMAS Project. 


\section{A. Experimental Test Rig and Setup}

The experimental test rig and setup for validating the motor with integrated filter inductor with $50 \%$ filter branch windings is shown in Fig. 10. For the purpose of verification, the windings of the $12 \mathrm{~S} / 10 \mathrm{P}$ permanent magnet machine were altered, with the practical implementation explained in section III. The prototype of the motor with integrated filter inductor is shown in Fig. 11 (a)-(c). The Spectra-Quest's "Drivetrain Diagnostic Simulator" test-rig is used [21] to test the integrated motor with HEMAS 3-phase voltage source inverter. The test rig and setup are equipped with a DC power supply, 3phase PWM voltage source inverter, 3 phase integrated motor, and the magnetic brake for mechanical loading on the machine under test. For the purpose of comparing both traditional and integrated motor drive systems, the RLC output filter is designed as described in section II. The EE-core filter inductor is built in-house as shown in Fig. 12(a), the parameters of which are shown in Table II. The inductor is constructed with 20 turns per phase and $0.4 \mathrm{~mm}$ airgap (paper was used to create the airgap) which gives the measured inductance of $1.15 \mathrm{mH}$. However, the airgap calculated from the design was $0.33 \mathrm{~mm}$ which results in the inductance discrepancy of $0.15 \mathrm{mH}$ in the measurement. The externally placed film type capacitors (KEMET, R46KR447050M2K, $4.7 \mu \mathrm{F}$ each) and wire wound damping resistors $(2 \Omega, 5 \mathrm{~W}$ power dissipation) are used, as shown in Fig. 12(b), in the presented study that can be integrated inside the motor housing by adopting the methodology discussed in Appendix I.

\section{B. Results of the Motor without Output Filter}

The motor shown in Fig. 2a without output filter is driven by inverter at the maximum speed of 2100 RPM and the load torque is varied between $1.5 \mathrm{Nm}$ to $3 \mathrm{Nm}$ in step of $0.5 \mathrm{Nm}$. Fig. 13(a) shows the inverter terminal voltage and the inverter currents flowing through the motor windings and their corresponding FFT is shown in Fig. 13(b).

\section{Results of the Motor with Integrated Filter Inductor and the Motor with Traditional Filter Inductor}

The experimental results of the motor with integrated filter inductor is shown in Fig. 14(a)-(c). Fig. 14(a) shows the inverter terminal voltage, motor branch voltage, filter branch and the motor branch current respectively, whereas, the FFT of motor branch voltage and current are illustrated in Fig. 14(c). Fig. 15(a)-(c) shows the same group of results for the motor with the traditional filter inductor. As expected, the filtering effect of the motor with integrated filter inductor and the motor with traditional filter inductor are similar in both simulation and experimental results. For the motor with traditional filter inductor, the magnitude of current ripple, on the motor's terminal at $20 \mathrm{kHz}$ is slightly higher (i.e. $330 \mathrm{~mA}$ ) as opposed to the motor with integrated filter inductor (i.e. $300 \mathrm{~mA}$ ). This is due to discrepancy in the inductance value of the EE-core inductor, in the manufacturing process. This phenomenon is also evident in Table III and FFT of the motor voltage and current, for both the cases, are illustrated in Fig. 14(c) and Fig. 15 (c) respectively.

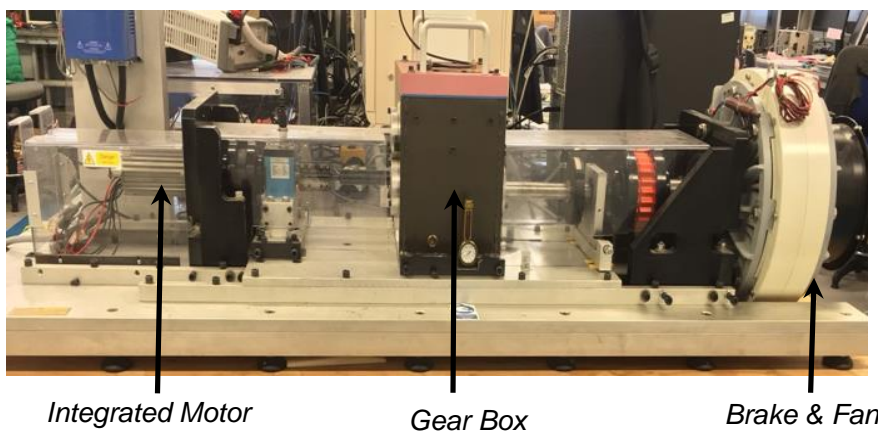

Fig.10: Experimental Rig - Spectra-Quest's Drivetrain Diagnostic Simulator
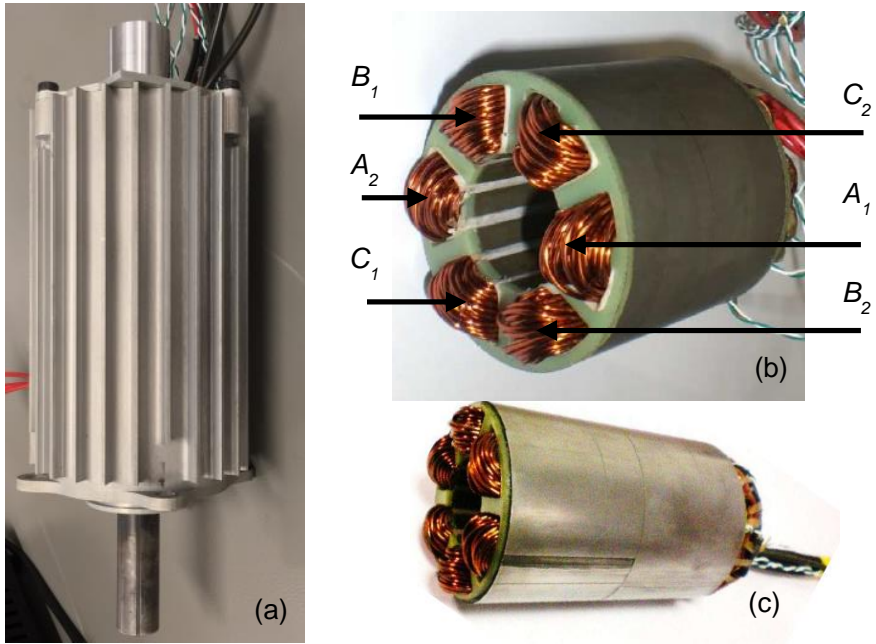

Fig.11: Prototype of Integrated Motor with Windings Pattern (a) Prototype with Housing (b) Prototype without Housing (c) Filter Branch $\left(\mathrm{A}_{1}, \mathrm{~B}_{1}\right.$ and $\left.\mathrm{C}_{1}\right)$ and Motor Branch $\left(\mathrm{A}_{2}, \mathrm{~B}_{2}\right.$ and $\left.\mathrm{C}_{2}\right)$ Windings
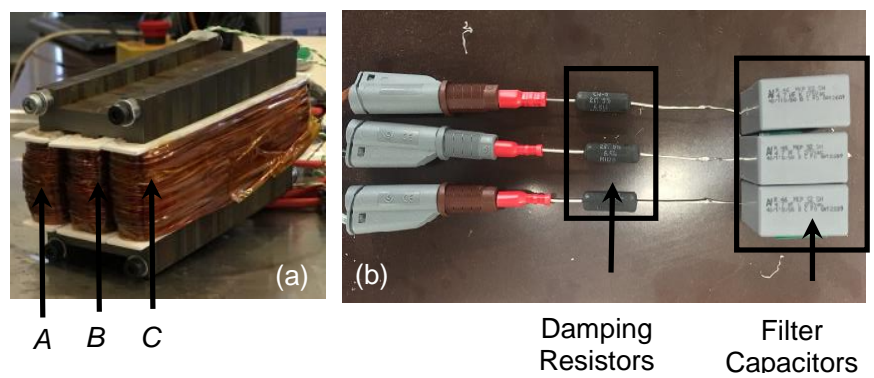

Fig.12: RLC Output Filter (a) Filter Inductor (b) Damping Resistors and Filter Capacitors

TABLE II

PARAMETERS OF EXTERNAL INDUCTOR

\begin{tabular}{lll}
\hline PARAMETERS & QUANTITY & UNIT \\
\hline Core Material & Non-Oriented Silicon & - \\
Required Inductance & 1.3 & $\mathrm{mH}$ \\
Measured Inductance & 1.15 & $\mathrm{mH}$ \\
Measured Resistance & 43.88 & $\mathrm{~m} \Omega$ \\
Effective Airgap & 0.04 & $\mathrm{~cm}$ \\
Turns per phase & 20 & - \\
Window Fill Factor & 0.5 & - \\
Window Area & 2.125 & $\mathrm{~cm}^{2}$ \\
Core Area & 8.5 & $\mathrm{~cm}^{2}$ \\
Conductor Area & 0.053 & $\mathrm{~A} / \mathrm{cm}^{2}$ \\
\hline
\end{tabular}



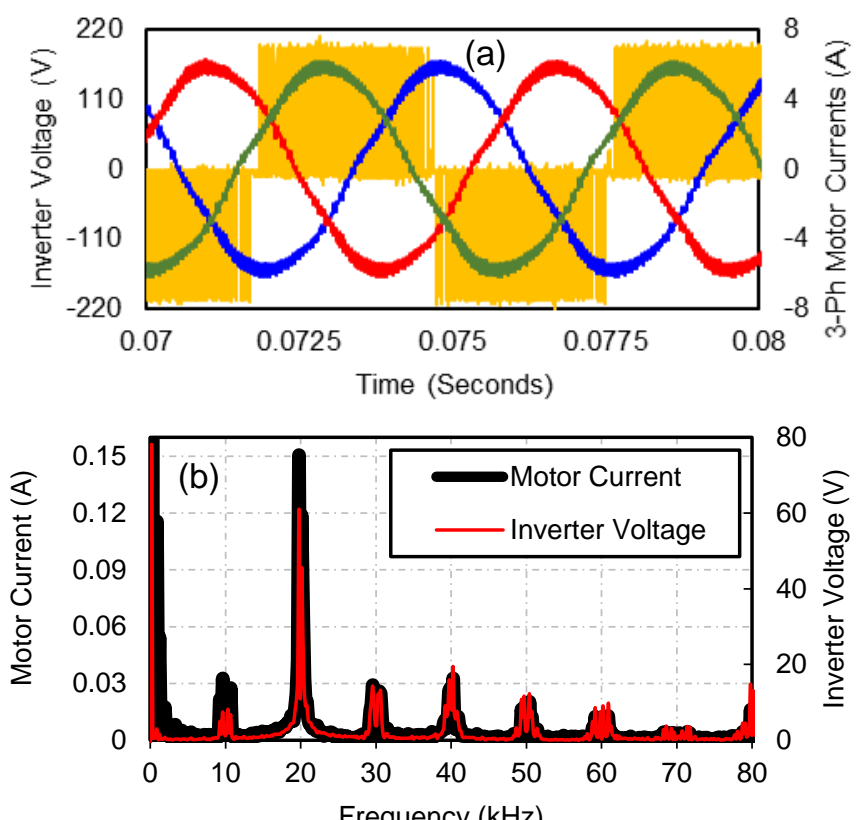

Fig.13: Experimental Results of the Motor without Output Filter (a) Inverter line-line terminal voltage, $\mathrm{V}_{\mathrm{AB}}$ and 3 phase line-line motor currents (b) FFT of inverter voltage and FFT of motor current
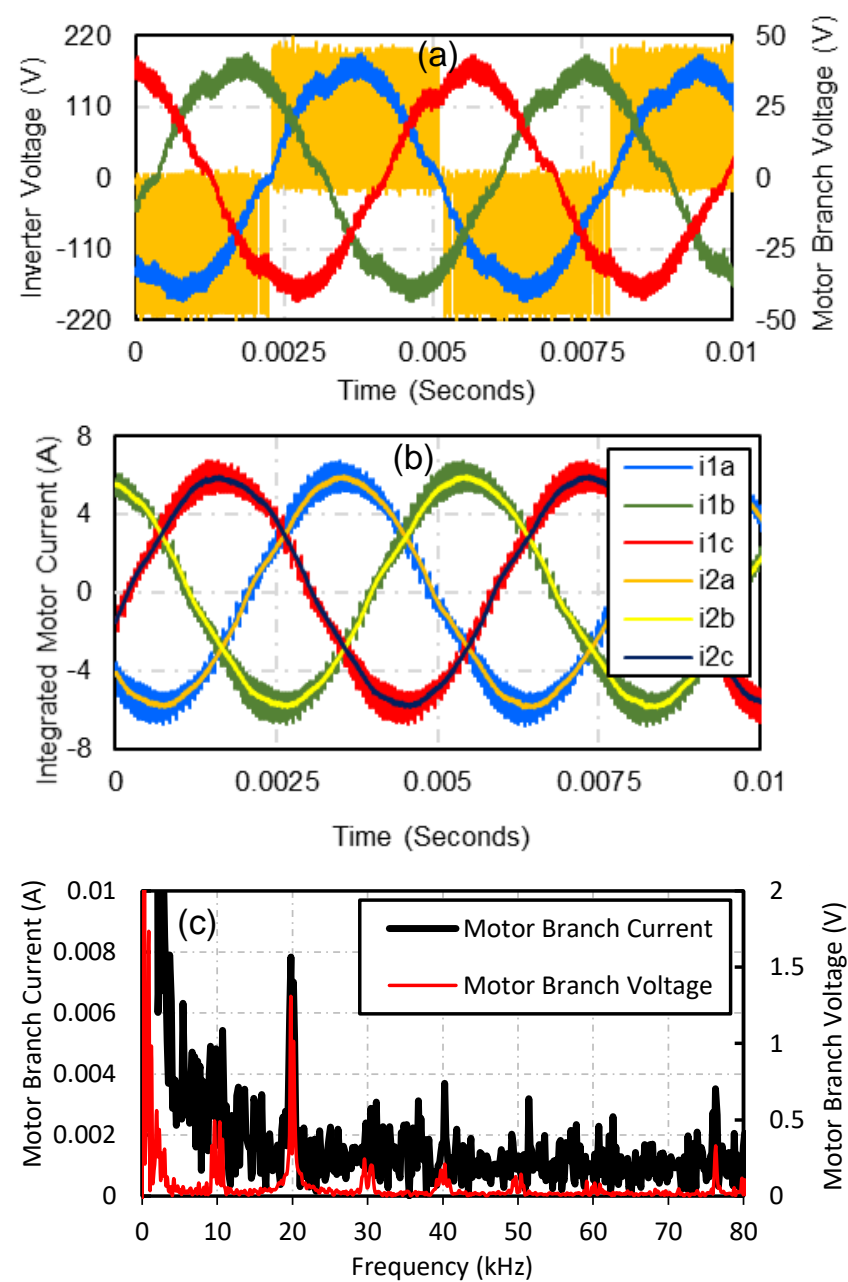

Fig.14: Experimental Results of the motor with Integrated Inductor (a) Inverter line-line terminal voltage, $\mathrm{V}_{\mathrm{C}-\mathrm{AB}}$ and 3-phase line-line filter branch voltages, $\mathrm{V}_{2, \mathrm{abc}}$ (b) 3-phase filter and motor branch currents, $\mathrm{i}_{\text {labc, }}, \mathrm{i}_{2 \mathrm{abc}}$ (c) FFT of motor branch voltage and FFT of motor branch current
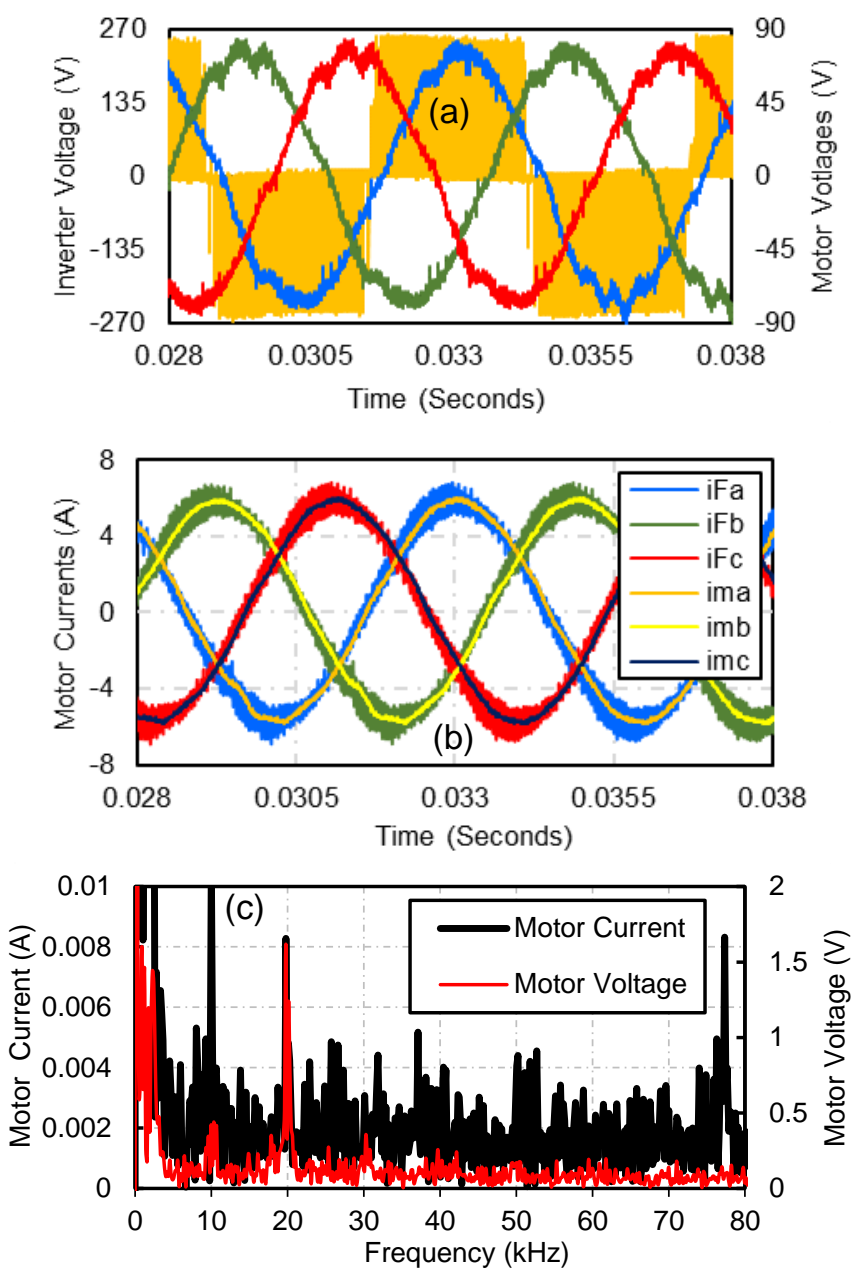

Fig.15: Experimental Results of the motor with Traditional Inductor (a) Inverter line-line terminal voltage, $\mathrm{V}_{\mathrm{C}-\mathrm{AB}}$ and 3-phase line-line motor voltages, $\mathrm{V}_{\mathrm{m}, \mathrm{abc}}$ (b) 3-phase filter and motor currents, $\mathrm{i}_{\mathrm{F}, \mathrm{abc}}, \mathrm{i}_{\mathrm{m}, \mathrm{abc}}$ (c) FFT of motor voltage, $\mathrm{V}_{\mathrm{m}, \mathrm{a}}$ and FFT of motor current, $\mathrm{i}_{\mathrm{m}, \mathrm{a}}$

Moreover, for the simulation results, the magnitude of voltage ripple at $20 \mathrm{kHz}$ is reduced by $98.5 \%$ and the magnitude of motor current is reduced by $97.2 \%$, when compared with motor operating without output filter. However, for the experimental results, the reduction in motor side voltage magnitude is greater for the motor with integrated inductor which has been brought to $1.31 \mathrm{~V}$ as opposed to $1.62 \mathrm{~V}$ obtained in the motor with traditional inductor.

\section{Magnitude of Motor Current Ripple}

The switching ripple component is evaluated in terms of filter and motor branch currents for the motor with the integrated inductor and motor current for the motor with the traditional inductor. Various tests were conducted in order to determine the switching current ripple. The ripple current is expressed in percentage of the fundamental value. The motor currents were measured at different speeds, mechanical loads and switching frequencies $(5,10$ and $15 \mathrm{kHz})$ of the inverter. The motor speed and mechanical load were varied from 1200 RPM to 2100 RPM and $1.5 \mathrm{Nm}$ to $3 \mathrm{Nm}$ respectively, at $10 \mathrm{kHz}$ switching frequency. The percentage current ripple of the motor with traditional and integrated inductor is shown in Fig. 16(a)-(f). It is observed that both filter and motor branch current ripple are reduced as the 
TABLE III

PERformance COMPARISON OF VOLTAGE AND CURRENT MAGNitude AT $20 \mathrm{KHz}$

\begin{tabular}{|c|c|c|c|c|c|c|}
\hline \multirow[b]{2}{*}{$\begin{array}{l}\text { PERFORMANCE } \\
\text { PARAMETERS }\end{array}$} & \multicolumn{3}{|c|}{ Simulation Results at $1.5 \mathrm{Nm}$ and $2100 \mathrm{RPM}$} & \multicolumn{3}{|c|}{ Experimental Results at $1.5 \mathrm{Nm}$ and $2100 \mathrm{RPM}$} \\
\hline & $\begin{array}{l}\text { Motor } \\
\text { without } \\
\text { Filter }\end{array}$ & $\begin{array}{l}\text { Motor with } \\
\text { Integrated Filter } \\
\text { Inductor }\end{array}$ & $\begin{array}{l}\text { Motor with } \\
\text { Traditional } \\
\text { Filter Inductor }\end{array}$ & $\begin{array}{l}\text { Motor } \\
\text { without } \\
\text { Filter }\end{array}$ & $\begin{array}{l}\text { Motor with } \\
\text { Integrated Filter } \\
\text { Inductor }\end{array}$ & $\begin{array}{l}\text { Motor with } \\
\text { Traditional } \\
\text { Filter Inductor }\end{array}$ \\
\hline Inverter Voltage Magnitude at $20 \mathrm{kHz}$ & $61.5 \mathrm{~V}$ & $61.5 \mathrm{~V}$ & $61.5 \mathrm{~V}$ & $62.3 \mathrm{~V}$ & $62.3 \mathrm{~V}$ & $62.3 \mathrm{~V}$ \\
\hline Inverter Current Magnitude at $20 \mathrm{kHz}$ & $117 \mathrm{~mA}$ & - & $234 \mathrm{~mA}$ & $150 \mathrm{~mA}$ & - & $330 \mathrm{~mA}$ \\
\hline Filter Branch Current Magnitude at $20 \mathrm{kHz}$ & - & $234 \mathrm{~mA}$ & - & - & $300 \mathrm{~mA}$ & - \\
\hline Motor Branch Voltage Magnitude at $20 \mathrm{kHz}$ & - & $0.92 \mathrm{~V}$ & - & - & $1.31 \mathrm{~V}$ & - \\
\hline Motor Branch Current Magnitude at $20 \mathrm{kHz}$ & - & $3.2 \mathrm{~mA}$ & - & - & $8.0 \mathrm{~mA}$ & - \\
\hline Motor Voltage Magnitude at $20 \mathrm{kHz}$ & - & - & $0.91 \mathrm{~V}$ & - & - & $1.62 \mathrm{~V}$ \\
\hline Motor Current Magnitude at $20 \mathrm{kHz}$ & - & - & $3.0 \mathrm{~mA}$ & - & - & $7.9 \mathrm{~mA}$ \\
\hline
\end{tabular}

TABLE IV

COMPARISON OF LOSSES, WEIGHT AND VOLUME

\begin{tabular}{llll}
\hline \multicolumn{1}{c}{$\begin{array}{c}\text { MOTOR } \\
\text { WITH }\end{array}$} & $\begin{array}{l}\text { Total Losses } \\
\text { at 3Nm } \\
\text { and175Hz }\end{array}$ & $\begin{array}{l}\text { External } \\
\text { Inductor } \\
\text { Weight }\end{array}$ & $\begin{array}{l}\text { External } \\
\text { Inductor } \\
\text { Volume }\end{array}$ \\
\hline Integrated Inductor & $177 \mathrm{~W}$ & 0 & 0 \\
External Inductor & $269 \mathrm{~W}$ & $2.2 \mathrm{Kg}$ & $754.3 \mathrm{~cm}^{3}$ \\
$\%$ Reduction & $34.2 \%$ & $100 \%$ & $100 \%$ \\
\hline
\end{tabular}
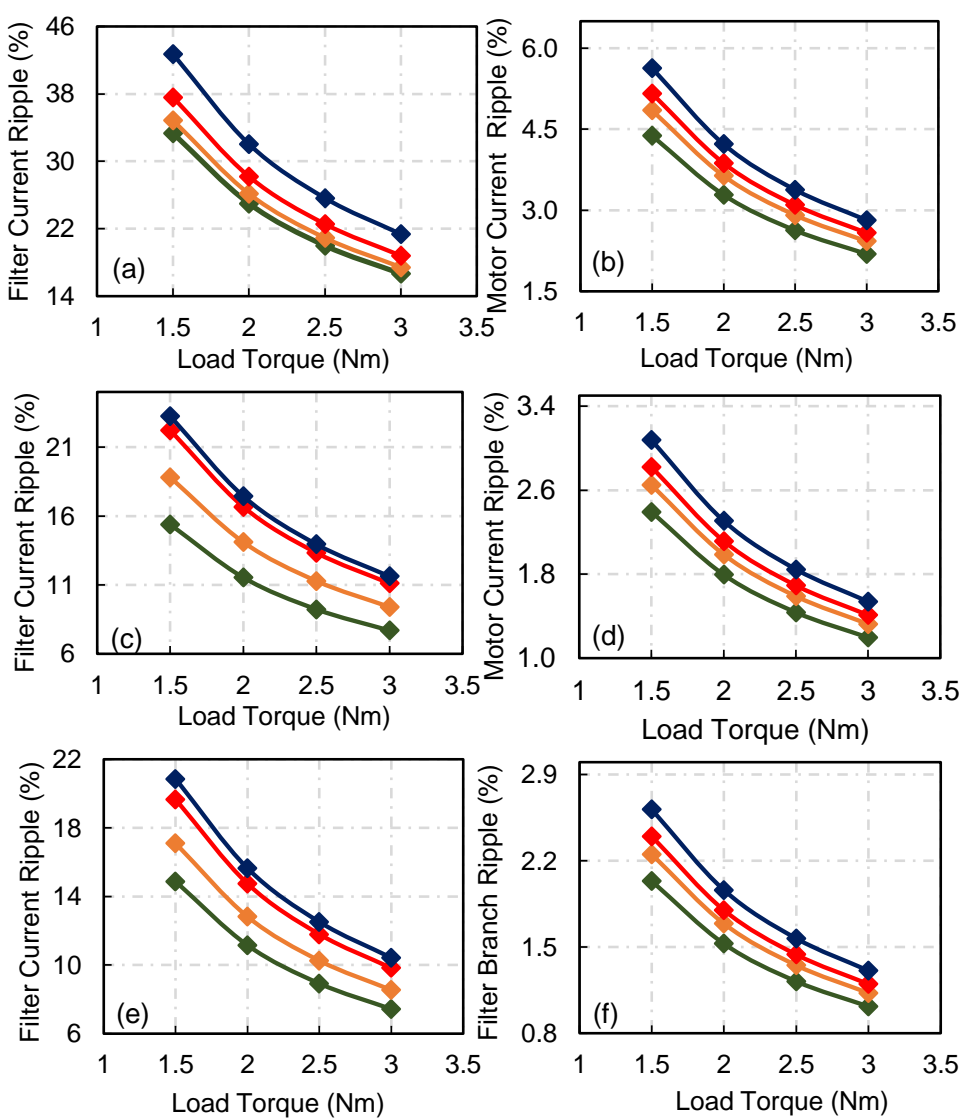

Fig.16: Magnitude Of Current Ripple at Different Switching Frequencies with Varying Rotor Speed and Mechanical Load (a) Filter current at 5kHz (b) Motor current at $5 \mathrm{kHz}$ (c) Filter current at $10 \mathrm{kHz}$ (d) Motor current at $10 \mathrm{kHz}$ (e) Filter current at $15 \mathrm{kHz}$ (f) Motor current at $15 \mathrm{kHz}$

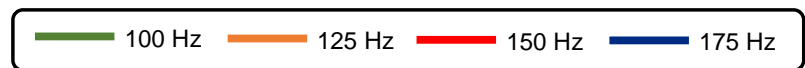

(a)

$\diamond 100 \mathrm{~Hz} \diamond 125 \mathrm{~Hz} \diamond 150 \mathrm{~Hz} \bullet 175 \mathrm{~Hz}$

(b)

Fig. 17: Classification of Symbolism for Fig. 16 (a) Current ripple of Motor with Integrated Inductor (b) Current ripple of Motor with Traditional Inductor

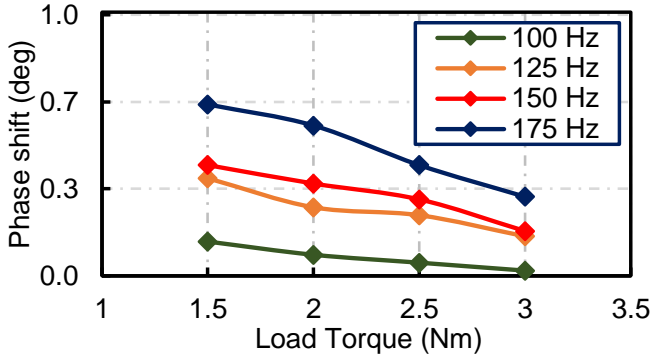

Fig. 18: Phase shift between filter branch current and the motor branch current load torque is increased, since the switching ripple component is solely dependent on the filter branch inductance (or filter inductance) which remains unchanged with the mechanical load on the motor. Another observation is the significant reduction of current ripple from $5 \mathrm{kHz}$ to $10 \mathrm{kHz}$, whereas, the reduction of current ripple from $10 \mathrm{kHz}$ to $15 \mathrm{kHz}$ is minimal which cannot be seen from the graphs illustrated in Fig. 16. The classification of symbolism for the motor with traditional and integrated inductor is shown in Fig. 17 which shows that the current ripple is very similar in Fig. 16, as expected, due to the identical filter inductance in both the cases.

\section{E. Phase shift between Filter and Motor Branch Current ( $\alpha$ )}

The addition of filter capacitor and damping resistor between motor windings produces a phase shift $(\alpha)$ between filter and the motor branch currents is shown in Fig. 18. This phase shift influences the electromagnetic torque developed by the motor as only filter branch current is controlled and the motor branch current is left uncontrolled. In order to see this effect, the phase shifts are estimated using the measured filter and the motor branch current at different rotor speed and load torque. As shown in Fig.18, the phase shift due to the RC branch is very small. This is because the filter RC branch is designed to act as a high impedance branch at lower frequencies and act as a low impedance branch beyond the resonance frequency, which will allow the high frequency ripple component to pass through it.

\section{F. Comparison of Total System Losses}

The motor losses were evaluated by measuring the input electrical power to the motor terminals and the output mechanical power delivered at the shaft. The motor losses were estimated by the difference of input electrical power and the output mechanical power as expressed in (20),

$$
P_{m, \text { loss }}=P_{\text {in }}-P_{\text {out }}=P_{\text {in }}-\left(T_{\text {out }} \cdot \omega_{r}\right)
$$


TABLE V

COMPARISON OF TOTAL SYSTEM VOLUME

\begin{tabular}{|c|c|c|c|c|c|c|c|c|c|}
\hline $\begin{array}{c}\mathrm{f}_{\mathrm{sw}} \\
(\mathrm{kHz})\end{array}$ & $\begin{array}{c}\mathrm{f}_{\text {res }} \\
(\mathrm{kHz})\end{array}$ & $\begin{array}{c}\text { Ratio } \\
\mathrm{f}_{\text {sw }} / \\
\mathrm{f}_{\text {res }}\end{array}$ & $\begin{array}{c}\text { Filter } \\
\text { Inductance } \\
(\mathrm{mH})\end{array}$ & $\begin{array}{c}\text { Filter } \\
\text { Capacitance } \\
(\mu \mathrm{F})\end{array}$ & $\begin{array}{c}\text { 3phase } \\
\text { Capacitor } \\
\text { Volume } \\
\text { (cm3) }\end{array}$ & $\begin{array}{c}\text { *EE-core } \\
\text { Inductor } \\
\text { Volume } \\
\text { (cm3) }\end{array}$ & $\begin{array}{c}* * \text { Motor } \\
\text { without Filter } \\
(\mathrm{cm} 3)\end{array}$ & $\begin{array}{c}\text { Traditional } \\
\text { Motor-drive } \\
\text { Volume }(\mathrm{cm} 3)\end{array}$ & $\begin{array}{c}\text { Integrated } \\
\text { Motor-drive } \\
\text { Volume }(\mathrm{cm} 3)\end{array}$ \\
\hline 5 & 1 & 5 & 1.3 & 19.5 & 232.8 & 529.9 & 482.8 & 1245.5 & 715.6 \\
\hline 10 & 2 & 5 & 1.3 & 4.7 & 37.6 & 529.9 & 482.8 & 1050.3 & 520.4 \\
\hline 15 & 3 & 5 & 1.3 & 2.2 & 22.47 & 529.9 & 482.8 & 1035.1 & 505.2 \\
\hline 20 & 4 & 5 & 1.3 & 1.2 & 22.73 & 529.9 & 482.8 & 1035.4 & 505.5 \\
\hline 25 & 5 & 5 & 1.3 & 0.8 & 8.42 & 529.9 & 482.8 & 1021.1 & 491.2 \\
\hline
\end{tabular}

* This excludes the volume of clipper that holds the inductor from vibration. The volume of core, active windings and end-windings are included. The volume of the inductor including clipper is $754.3 \mathrm{~cm}^{3}$ which is already mentioned in Table IV.

** Housing volume added in the motor volume.

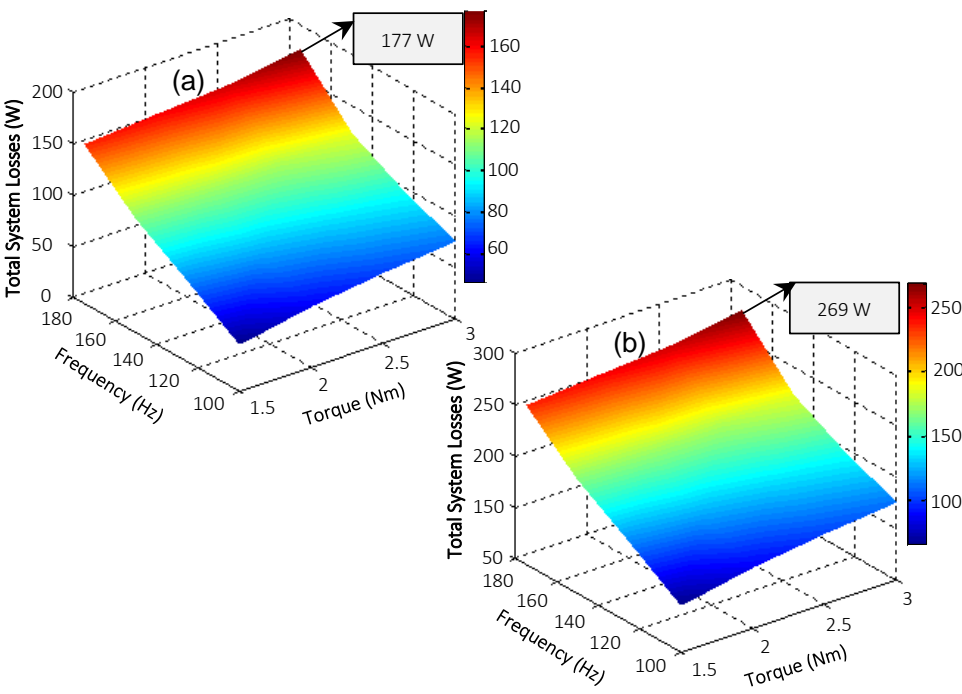

Fig.19: Total System Loss Comparison (a) Motor with Integrated Inductor (b) Motor with Traditional Inductor

(a)

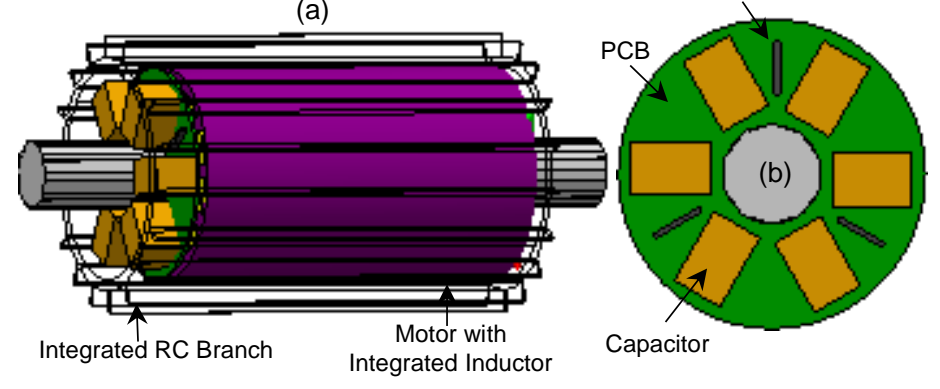

Fig. 20: Integration of RC Branch (a) Axial view of the motor and PCB (b) Radial view of the damping resistors and filter capacitors mounted on the PCB

where, $P_{\text {in }}$ is the input electrical power in watts, $P_{\text {out }}$ is the output mechanical power in watts, $T_{\text {out }}$ is the measured output torque in $\mathrm{Nm}$ and $\omega_{r}$ is rotor speed in $\mathrm{rad} / \mathrm{s}$. The motor losses were measured at different rotor speed and mechanical load whilst keeping the inverter switching frequency at $10 \mathrm{kHz}$. The motor speed is varied from 1200 RPM to 2100 RPM in step of 300 RPM, whereas, the load torque is applied from $1.5 \mathrm{Nm}$ to $3 \mathrm{Nm}$ in steps of $0.5 \mathrm{Nm}$. Fig. 19(a)-(b) shows the total loss comparison of the motor with integrated inductor and the motor with traditional inductor, respectively, at the fundamental frequency of $100 \mathrm{~Hz}, 125 \mathrm{~Hz}, 150 \mathrm{~Hz}$ and $175 \mathrm{~Hz}$. It must be noted that only losses are compared in this paper for the motor with traditional and integrated inductor. The efficiency of the overall system should be computed based on the rated torque and speed of the machine reported in Table I.

As can be seen from Fig. 19 that the total losses in the motor with traditional filter inductor are higher than the motor with integrated filter inductor due to the added losses of external inductor component (i.e. EE-core). The major loss component in the external inductor comes from the iron core (Material M250 35A Non-oriented Mild Steel). These losses have significantly reduced when the motor with integrated inductor is used that shares the Cobalt Iron material (Vacoflux-50) with the motor. One may be argued why the external inductor core material is not same as the motor. This is completely a trade-off between the material's cost and loss. The material Vacoflux-50 incurs small amount of core loss as compared to the material M250 Steel, which comes at the expense of relatively higher cost. In [26], the study suggests that the cost of the Vacoflux50 can go as high as 20 times the conventional M250 nonoriented mild steel. Moreover, it is rare to have an external inductor made from Cobalt Iron purely, due to the small amount of material that would be required to manufacture the inductor as opposed to the motor.

The weight and volume comparison of the motor with integrated filter inductor and the motor with traditional filter inductor is shown in Table IV. It is clearly seen that the motor with integrated filter inductor, entirely, eliminates the losses, weight and volume associated with it for the integrated motordrive system.

\section{G. Comparison of Total System Volume}

The impact of varying switching frequency on the volume of the motor drive system is presented in this section since changing the switching frequency will change capacitor size, if the ratio between switching frequency and resonance frequency is constant. Table $\mathrm{V}$ shows the volume comparison for motor without filter, motor with integrated inductor and motor with EE-core inductor, when the frequency ratio $\left(f_{\mathrm{sw}} / \mathrm{f}_{\text {res }}\right)$ is 5 . This will keep the same level of attenuation for the filter circuit as in the original case, presented in the previous section when switching frequency is $10 \mathrm{kHz}$. The required capacitances were estimated based on the resonance frequency, whilst, keeping the filter inductance constant. Subsequently, the volume of the 3phase capacitors was evaluated using the data sheets (KEMET capacitors from Farnell UK). It can be seen that the overall volume of the motor with integrated inductor is reduced when 
the switching frequency is increased beyond $10 \mathrm{kHz}$. As expected, there is a reduction in volume as we go higher in switching frequency (higher than $10 \mathrm{kHz}$ ), however, the gain is negligible. Moreover, there is a sharp drop in volume from 5 $\mathrm{kHz}$ to $10 \mathrm{kHz}$ but after $10 \mathrm{kHz}$ the gain is significantly reduced. As a result, $10 \mathrm{kHz}$ switching frequency was selected as an optimal for realisation of the system.

When compared with the motor without filter at $10 \mathrm{kHz}$ switching frequency, just $7.8 \%$ increase in the system volume is realised for the motor with integrated inductor, whereas, system volume of the motor with traditional inductor is increased by $117.6 \%$. On the other hand, $50.5 \%$ system volume is reduced when the volume of integrated motor drive is compared with the volume of traditional motor drive, at $10 \mathrm{kHz}$ switching frequency.

\section{CONCLUSIONS}

A novel concept of the permanent magnet motor with integrated filter inductor was presented in this paper. The motor with integrated filter inductor eliminates the need of a separate filter inductor which removes the losses, weight and volume associated with it. The experimental results have shown that the integrated motor is feasible and can practically be implemented, particularly where bulky and lossy inductors are used for AC motor-drive systems. The integrated motor was tested and verified with $50 \%$ filter branch windings, for comparison purpose, in the MATLAB/Simulink tool. The filtering effect of the motor with integrated inductor and the motor with traditional inductor were comparable, however, the torque ripple (switching) was higher in the motor with integrated filter inductor. This is due to the presence of inverter switching component in the motor branch windings unlike the motor with traditional filter inductor. The total system losses were measured and compared between integrated and traditional drives, which showed a significant reduction of the losses in the motor with integrated inductor. The total losses in the motor with integrated inductor were reduced by $34.2 \%$ at $175 \mathrm{~Hz}$ and $3 \mathrm{Nm}$ load whereas, its weight and volume were eliminated.

\section{FUTURE WORK}

To get utmost benefit from the motor with integrated filter inductor, the optimisation of filter branch windings is required since decrease in filter inductance will increase the requirement of the filter capacitance, for the same resonance frequency and attenuation level. Higher portion of motor branch windings will experience the filtered currents if the percentage of the filter branch windings is reduced. In this case, a part of the motor branch windings is still wound on the same slots of the filter branch windings that will produce a transformer action between them (i.e. filter and motor branch windings). This transformer action will cancel out the switching component whilst reducing the losses caused by the high frequencies, due to the cancellation effect. The experimentation of this concept is currently being performed that will be documented and presented in the future publication, in order to optimally choose a portion of the filter branch windings.

\section{APPENDIX - I}

\section{A. Integration of $R C$ Branch}

Since the RC branch is placed outside the motor it is possible to integrate RC components inside the motor's housing. The 3phase capacitors and resistors can be axially mounted and arranged in a pattern on the PCB [5, 21] as shown in Fig. 20. The conceptual example shown in Fig. 20 can consist of 3 (or multiple of 3) capacitors to be integrated inside the machine's enclosure. The choice between different technologies of capacitors, considering integration application, depends on the cost and reliability. In terms of cost, the film capacitor technologies would be a suitable option to integrate the capacitance inside the housing as they are the most flexible in terms of device geometry which makes it attractive for integration applications [22]. However, their volumetric power density is low, and the insulation resistance changes greatly with temperature which can eventually lead to a thermal runaway [23]. On the other hand, if reliability is the major concern then "CeraLink" ceramic capacitor is the ideal choice for integration as it offers significant insulation resistance until $200^{\circ} \mathrm{C}$. In addition to this, it provides higher volumetric power density than film capacitors, therefore, making it more suitable for space-restricted, high temperature integration applications [24-25].

\section{REFERENCES}

[1] S. Kimura, Y. Itoh, W. Martinez, M. Yamamoto, and J. Imaoka, "Downsizing Effects of Integrated Magnetic Components in High Power Density DC-DC Converters for EV and HEV Applications," IEEE Transactions on Industry Applications, vol. 52, pp. 3294-3305, 2016.

[2] J. Scoltock, G. Calderon-Lopez, Y. Wang, and A. J. Forsyth, "Design optimisation and trade-offs in multikW DC-DC converters," in 2016 IEEE Energy Conversion Congress and Exposition (ECCE), 2016, pp. 1-8.

[3] A. Walker, G. Vakil and C. Gerada, "Novel Core Designs to Miniaturise Passive Magnetic Components," 2018 IEEE Transportation Electrification Conference and Expo (ITEC), Long Beach, CA, 2018, pp. 644-649.

[4] M. R. Khowja, C. Gerada, G. Vakil, R. Abebe, S. Odhano, C. Patel, et al., "Novel Motor-Shaped Rotational Inductor for Motor Drive Applications," in IEEE Transactions on Industrial Electronics, vol. 67, no. 3, pp. 18441854, March 2020. DOI: 10.1109/TIE.2019.2907512

[5] Robert Abebe, Gaurang Vakil, Giovanni Lo Calzo, Thomas Cox, Simon Lambert, Mark Johnson, Chris Gerada, Barrie Mecrow "Integrated motor drives: state of the art and future trends" IET Electric Power Applications.

[6] M. Raza Khowja, C. Gerada, G. Vakil, P. Wheeler and C. Patel, "Integrated output filter inductor for permanent magnet motor drives," IECON 2016. Conference of IEEE Industrial Electronics Society

[7] M. Raza Khowja, C. Gerada, G. Vakil, P. Wheeler and C. Patel, "Novel integrative options for passive filter inductor in high speed AC drives," IECON 2016. Conference of IEEE Industrial Electronics Society.

[8] M. Raza Khowja, C. Gerada, G. Vakil, S. Quadir Quadri, P. Wheeler and C. Patel, "Design of an Integrated Inductor for $45 \mathrm{~kW}$ Aerospace StarterGenerator," 2018 IEEE Transportation Electrification Conference and Expo (ITEC), Long Beach, CA, 2018, pp. 570-575.

[9] M. Raza Khowja, C. Gerada, G. Vakil, C. Patel and P. Wheeler, "Design optimization of integrated rotor-less inductors for high-speed AC drive applications," 2017 IEEE Workshop on Electrical Machines Design, Control and Diagnosis (WEMDCD), Nottingham, United Kingdom, 2017

[10] Colonel Wm. T. Mclyman "Transformer and Inductor Design Handbook", Fourth Edition

[11] Naayagi R.T, Forsyth A.J. "Design of high frequency air-core inductor for DAB converter" Power Electronics, Drives and Energy Systems (PEDES), 2012 IEEE International Conference. Publication Year: 2012 
[12] Meere R, Ningning Wang, O'Donnell T, Kulkarni S, Roy S, O'Mathuna, S.C. "Magnetic-Core and Air-Core Inductors on Silicon: A PerformanceComparison up to $100 \mathrm{MHz}$ " Magnetics, IEEE Transactions.

[13] Nee B.M, Chapman P.L. "Integrated Filter Element in Electric Drives" Vehicle Power and Propulsion Conference, 2007.

[14] Garvey S.D. Norris, W.T, Wright M.T. "The role of integrated components in protecting motor windings". Electric Power Applications, IEEE Proceedings - Volume: 147.

[15] Nakajima, Yuki Imazu, Tomoya Mizukoshi, Yukio Sato, Sho Zushi, Yusuke "Integrated Capacitor Type Stator", Patent No. 8049383

[16] M. A. Mohamed, S. M. Lambert, B. C. Mecrow, D. J. Atkinson and A. C. Smith, "An electrical machine with integrated drive LCL filter components," 8th IET International Conference on Power Electronics, Machines and Drives (PEMD 2016), Glasgow, 2016, pp. 1-6.

[17] M. A. S. Mohamed, S. M. Lambert, B. C. Mecrow, X. Deng, S. Ullah and A. C. Smith, "Integrating the magnetics of an LCL filter into a high speed machine with pre-compressed coils," 2017 IEEE International Electric Machines and Drives Conference (IEMDC), Miami, FL, 2017, pp. 1-7.

[18] Sozer Y, Torrey D.A, Reva S. "New inverter output filter topology for PWM motor drives" Applied Power Electronics Conference APEC 2000.

[19] A. Reznik, M. G. Simões, A. Al-Durra and S. M. Muyeen, "\$LCL\$ Filter Design and Performance Analysis for Grid-Interconnected Systems," in IEEE Transactions on Industry Applications, vol. 50, no. 2, pp. 12251232, March-April 2014.

[20] SpectraQuest. Available at: http://spectraquest.com/drivetrain/details/dds

[21] X. Deng, S. Lambert, B. Mecrow, and M. A. S. Mohamed, "Design Consideration of a High-Speed Integrated Permanent Magnet Machine and its Drive System," in 2018 XIII International Conference on Electrical Machines (ICEM), 2018, pp. 1465-1470.

[22] Sarjeant W. J., Zirnheld J., MacDougall F. W., "Capacitors", IEEE Transactions on Plasma Science, 1998. 26, (5), 1368-1392

[23] Caliari L., Bettacchi P., Boni E., et al., "KEMET film capacitors for high temperature, high voltage and high current", CARTS International Proceedings - ECA, 2013

[24] J.Konrad, M. Koini, M. Schossmann, M. Puff, "New demands in DC link power capacitors" Congress on Automotive Electronic Systems - 3rd and 4th December 2014. EPCOS OHG A TDK Group company Siemensstrasse 438530 Deutschlandsberg, AUSTRIA

[25] H. Wang and F. Blaabjerg, "Reliability of Capacitors for DC-Link Applications in Power Electronic Converters-An Overview," in IEEE Transactions on Industry Applications, vol. 50, no. 5, pp. 3569-3578, Sept.-Oct. 2014

[26] D. Gerada, A. Mebarki, N. L. Brown, C. Gerada, A. Cavagnino and A. Boglietti, "High-Speed Electrical Transactions on Industrial ElectronicsMachines: Technologies, Trends, and Developments," in IEEE Transactions on Industrial Electronics, vol. 61, no. 6, pp. 29462959, June 2014

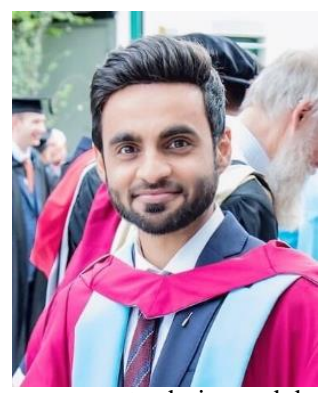

Muhammad Raza Khowja (M'19) received the B.Eng. (Hons) degree in Electrical Power Engineering from Mehran University of Engineering \& Technology, Jamshoro, Pakistan, in 2011. He received his MSc degree in Electrical Engineering in 2012. He has received his $\mathrm{PhD}$ degree in Electrical \& Electronics Engineering in 2018 from The University of Nottingham, UK where he is currently working as a Research Fellow in Power Electronics, Machines, and Control (PEMC) Group. His main research interest include integrated design of passive components, design and development of high-performance electrical machines for aerospace applications winding insulation charaterization and lifetime evaluation of electrical machines.

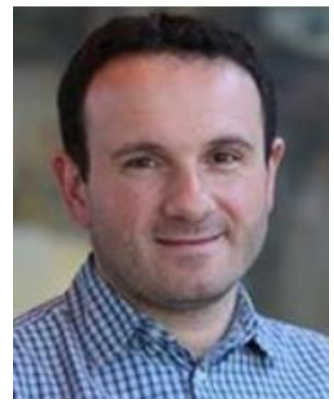

Chris Gerada (M'05) received the Ph.D. degree in numerical modeling of electrical machines from the University of Nottingham, Nottingham, U.K., in 2005. He subsequently worked as a Researcher with the University of Nottingham on highperformance electrical drives and on the design and modeling of electromagnetic actuators for aerospace applications. Since 2006, he has been the Project Manager of the GE Aviation Strategic Partnership. In 2008, he was appointed as a Lecturer in the electrical machines; in 2011, as an Associate Professor; and in 2013, as a Professor at the University of Nottingham. His main research interests include the design and modeling of high-performance electric drives and machines. Prof. Gerada is an Associate Editor for the IEEE TRANSACTIONS ON INDUSTRY APPLICATIONS and is the past Chair of the IEEE IES Electrical Machines Committee.

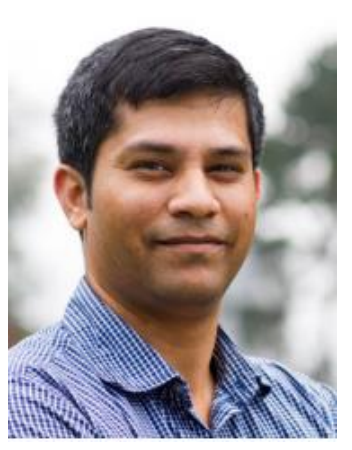

Gaurang Vakil (M'16) received the Ph.D. degree in variable speed generator design for renewable energy applications from the Power Electronics, Machines and Drives Group, Indian Institute of Technology-Delhi, New Delhi, India, in 2016. He subsequently worked as a Research Associate with the Power Electronics, Machines and Controls Group, University of Nottingham, Nottingham, U.K. In 2016, he was appointed as an Assistant Professor within the Electrical and Electronics Engineering Department, University of Nottingham. His main research interests include design and development of highperformance electrical machines for transport and propulsion, optimizing electric drive-train for pure electric and hybrid vehicles (aerospace and automotive), high power density machines, and magnetic material characterization.

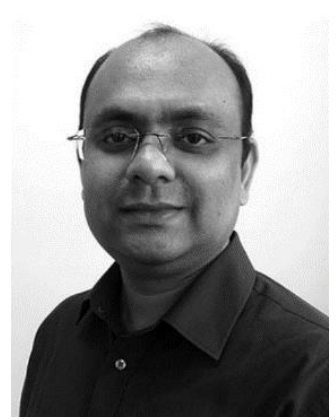

Chintan Patel (S'08-M'12) received the Ph.D. degree from the Centre for Electronics Design and Technology, Indian Institute of Science, Bangalore, India, in 2011. He has been a Research Fellow with Power Electronics, Control and Machines Group, The University of Nottingham, Nottingham, U.K., since March 2011. His current research interests include applications of the power electronic converter for electromechanical actuation and aircraft electrical power systems. 


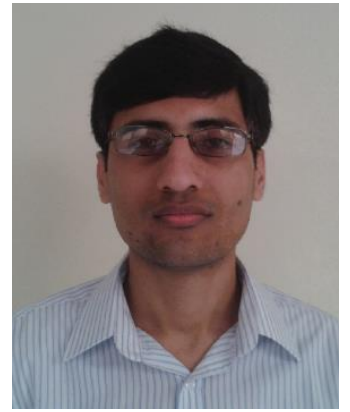

Shafiq Odhano (S'13-M'15-SM'20) received the M.Sc. degree in electrical engineering and the $\mathrm{Ph} . \mathrm{D}$. degree in power electronics, machines, and drives from the Politecnico di Torino, Turin, Italy, in 2014. He has been affiliated with the Politecnico di Torino as a postdoctoral research fellow and with the University of Nottingham, UK, as a research fellow. He is currently a lecturer in electric drives at Newcastle University, Newcastle Upon Tyne, UK. His research interests include high-performance control of servodrives, model predictive control of power converters, and self-commissioning of ac motor drives. Dr. Odhano was a recipient of the IEEE-IAS Prize Paper Award, in 2015.

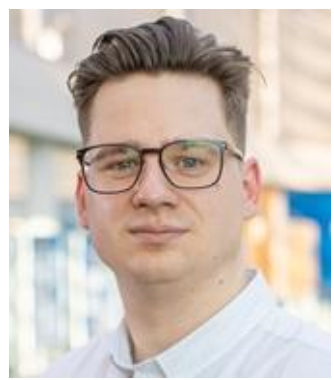

Adam Walker (M'18) received the Ph.D. degree in electrical machines design from the University of Nottingham, Nottingham, U.K., in 2016. Previously, he was a Research Associate with the University of Nottingham, Nottingham, U.K., where he is currently an Assistant Professor of electrical machines and drives with the Power Electronics Machines and Control group. His main research interests include electrical machines for traction applications, both personal vehicle and heavy duty vehicles, but is also interested in thermal management of machines and design of passive magnetic components.

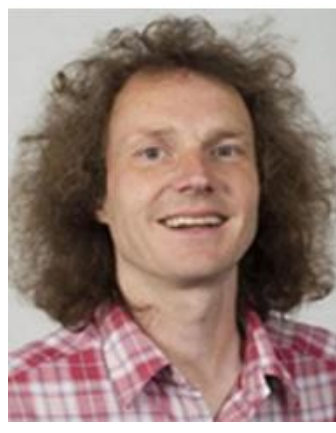

Pat Wheeler (M'94-SM'08) received the B.Eng. (Hons.) degree in electrical engineering and the Ph.D. degree in electrical engineering from the University of Bristol, Bristol, U.K., in 1990 and 1994, respectively. In 1993, he moved to the University of Nottingham and worked as a Research Assistant with the Department of Electrical and Electronic Engineering. In 1996, he became a Lecturer with the Power Electronics, Machines and Control Group, University of Nottingham, where he has been a Full Professor since January 2008. He was the Head of the Department of Electrical and Electronic Engineering, University of Nottingham from 2015 to 2018 . He is currently the Head of the Power Electronics, Machines and Control Research Group and is the Li Dak Sum Chair Professor in electrical and aerospace engineering with the University of Nottingham Ningbo China, Ningbo, China. He has published 500 academic publications in leading international conferences and journals. Dr. Wheeler is a member of the IEEE PELs AdCo and was an IEEE PELs Distinguished Lecturer from 2013 to 2017. 